УДК 902/904

https://doi.org/10.24852/2587-6112.2021.4.57.67

\title{
НОВЫЕ СРЕДНЕВЕКОВЫЕ ЗАХОРОНЕНИЯ БУРЯТИИ: КУЛЬТУРНАЯ АТРИБУЦИЯ И ХРОНОЛОГИЯ ${ }^{1}$
}

\author{
(c) 2021 г. Б.А. Базаров, Н.В. Именохоев, Д.А. Миягашев, Я.В. Дикий
}

На современном этапе темпы изучения средневекового периода в истории Западного Забайкалья значительно спали. В настоящей статье приводятся предварительные материалы раскопок трех средневековых погребений двух новых могильников-Нижний Мангиртуй, пункт 1 и 2 и Нур-Тухум, пункт 2. Актуальным остается вопрос культурной атрибуции погребений эпохи средневековья и определение их хронологической позиции. Предлагается сузить хронологические рамки раннемонгольской археологической культуры с сохранением хойцегорской и саянтуйской этапов. Эпоху Великой империи XIII-XIV вв., следующей вслед за раннемонгольской культурой, предложено называть монгольским временем. Решение стоящих перед археологией вопросов хронологии средневековья Бурятии видится в усилении работы по радиоуглеродной датировке погребальных и поселенческих комплексов.

Ключевые слова: археология, средневековье, раннемонгольская археологическая культура, погребения, Бурятия.

\section{NEW MEDIEVAL BURIALS OF BURYATIA: CULTURAL ATTRIBUTION AND CHRONOLOGY ${ }^{2}$}

\section{B. A. Bazarov, N. V. Imenokhoev, D. A. Miyagashev, Dikiy Ya. V.}

At the modern stage, the pace of research of medieval period in history of Western Transbaikalia dropped significantly. The paper presents preliminary results of the excavations of three medieval tombs of two recent discovered burial grounds - Nizhniy Mangirtuy 1 and 2 and Nur-Tukhum 2. The issue of cultural attribution of medieval burials and determination of their chronological position is still relevant. It is proposed to restrict the chronological boudaries of the Early Mongolian archaeological culture and keep the classification for the Khoyzegor and Sayantui stages. The era of the Great Empire of the XIII-XIV centuries rised after the early Mongolian culture, is proposed to be called the Mongolian time. To resolve the issues of the chronological dividing of the Middle Age of Buryatia facing archeology is need the increasing of radiocarbon dating of burial and settlement complexes.

Keywords: archaeology, middle age, early-mongols archaeological culture, burials, Buryatia.

В историографии существуют различные мнения по поводу определения средневековья. Исследователи восточноевропейских кочевых древностей оперируют эпохой, где раннее средневековье определено периодом IV - первой половиной X века; этап развитого средневековья - второй половиной $\mathrm{X}$ - первой половиной XIV вв.; падение Золотой Орды считается началом эпохи позднего средневековья» (Археология СССР, 1981, с. 8).

Для анализа исторических процессов, протекавших в Центральной Азии, бурятские археологи «придерживаются следующей схемы внутренней периодизации эпохи: раннее средневековье - конец II в. - середина VI в. н.э - периоды Сяньбийской державы и Жужаньского каганата; развитое средневековье-VII-XIV вв. - периоды Тюркских и Уйгур-

ского каганатов, Киданьской и Монгольской империй; позднее средневековье - XV-XVII вв. - период раздробленности Монгольского государства, маньчжурской экспансии и русской колонизации в Центральной Азии и Сибири» (История Бурятии, 2011, с. 203). Этот громадный хронологический период в истории Центральной Азии характеризуется обилием политических событий, оказавших огромное влияние на развитие многочисленных групп населения различного этнического происхождения - монгольского, тюркского, тунгусского, древнего самодийского и индоиранского, находившихся на разных ступенях экономического и культурного развития. Степные и лесостепные территории северной периферии региона оказались в зоне их активного освоения кочевыми государствами тюрков, уйгуров,

\footnotetext{
Работа выполнена в рамках государственного задания (проект «Историческое пространство монгольского мира: археологические культуры, общества и государства», № 121031000241-1). 2 The work was carried out within the framework of the state task
world: archaeological cultures, societies and states", No. 121031000241-1).
} 


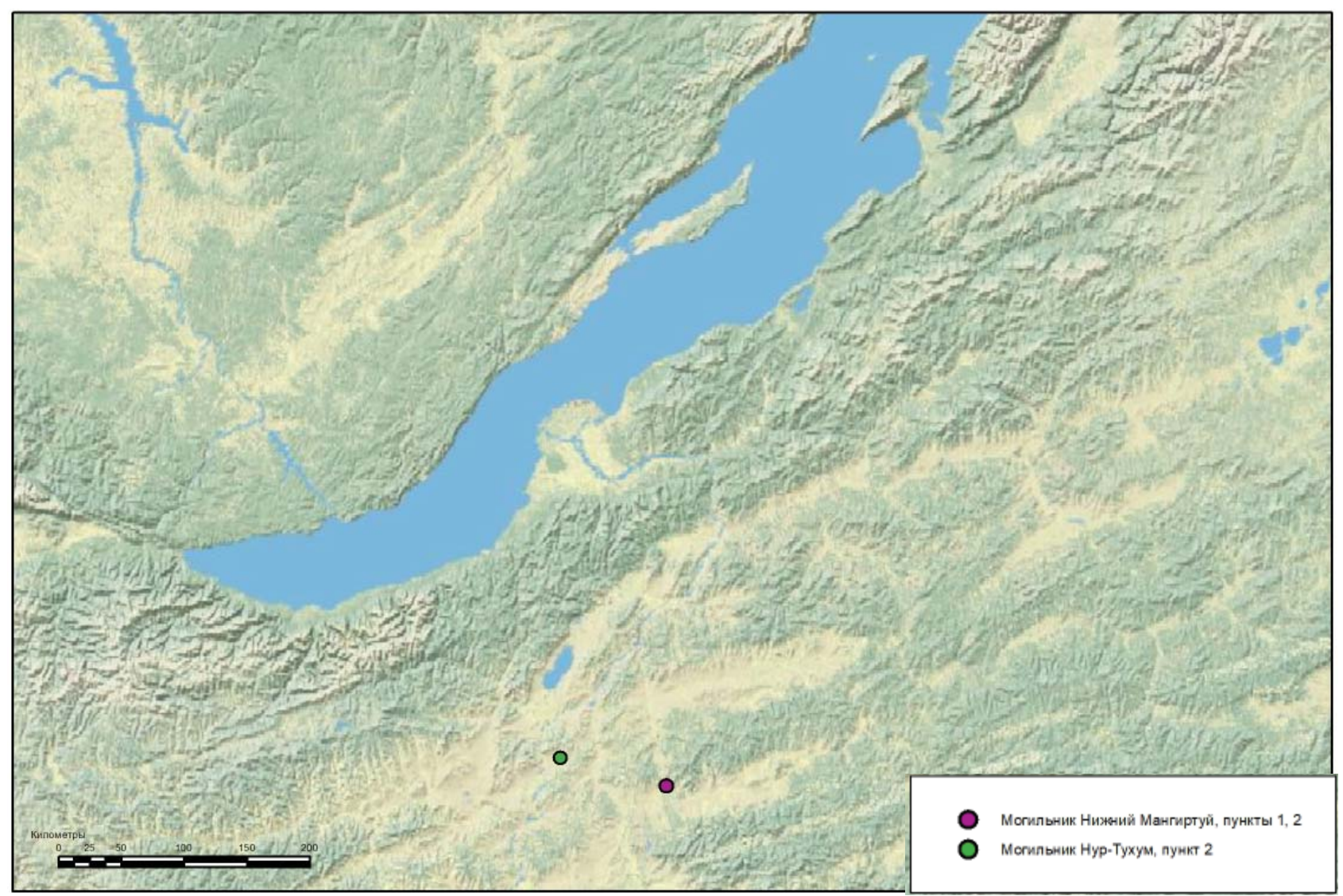

Рис. 1. Карта-схема расположения средневековых могильников

Fig. 1. Sites under study

монголов. Воинственные кочевники захватывали и осваивали новые территории, частично уничтожая или же присоединяя местное население к своим племенным союзам. В результате такого диффузионного процесса появлялись предпосылки для возникновения и формирования новых этнических общностей с измененной этнолингвистикой, антропологией, материальной и духовной культурой, ставших впоследствии основой современных народов. По сведениям письменных источников, представленных китайскими династийными хрониками, историческими сочинениями персидских, арабских, армянских, грузинских авторов, путевыми заметками европейских дипломатов и купцов, известно, что в Центральной Азии в эпоху средневековья длительное время проживало двуязычное население, состоявшее в основном из потомков древних народов хунну и дунху. После гибели и исхода сохранивших боеспособность части населения хуннской империи на западные окраины Великой степи, «остатки сего народа, простиравшегося еще до 100,000 кибиток» принимает народное имя сяньби, и с этого времени в центральноазиатских степях вплоть до VI в. устанавливается приоритет монголоязычных племен (Бичурин, 1828, с.
53). Смена языкового доминирования произошла с гибелью Жужаньского каганата, состоявшего из различных по этническому или родовому происхождению групп населения при преобладании монголоязычного субстрата. Середина I тыс. н.э. ознаменовалась созданием династией Ашина тюркского каганата, в который вошли не только племена Алтая, но и все народы Центральной Азии и Восточного Туркестана. В Х в. степи вновь переходят под господство монголоязычных народов - киданей империи Ляо. Преемниками киданей стали монголы, образовавшие при Чингис-хане величайшую империю древности, равной которой не основывал ни один ни кочевой, ни оседлый народ средневековья.

Первые исследования памятников средневековья на территории Бурятии были начаты в XIX столетии. В период 1851-1855 гг. учитель, известный поэт и член Сибирского Отделения Императорского Русского Географического Общества Д. Давыдов раскопал четыре средневековых кургана в местности Савелов Крест, восточнее г. Верхнеудинска. Погребения, ориентированные длинной осью на восток-юго-восток, были полностью ограблены. Лишь в одном кургане на глубине около двух метров расчищены кости ног 
человека и несколько обломков ребер. Фрагменты других костей, в обломках, попадались в заполнении могильной ямы. Череп и длинные кости рук не найдены (Давыдов, 1856, с. 89). В 1861 г. горный инженер И.А. Лопатин, занимаясь составлением геологической карты Витимского плоскогорья, упоминает о баргутских оросительных канавах, землянках и могильниках, распространенных в долине р. Баргузин (Лопатин, 1867). В конце XIX столетия члены Русского географического общества - Н.В. Кириллов обнаружил тюркскую руническую надпись и погребения в берестяных гробах в долине р. Тарбагатайки (Кириллов, 1897), а Ю.Д. Талько-Грынцевич в среднем течении р. Селенги, в долинах рек Хилок и Чикой исследовал захоронения «в деревянных гробах, обернутые в бересту» или «в выдолбленной колоде», которые датировал средневековым периодом (Талько-Грынцевич, 1900, с. 48-50). Ю.Д. Талько-Грынцевичу принадлежит первая классификация древних погребений, состоящей из четырех разновременных групп. Захоронения четвертой группы с невысокой земляной насыпью, обложенные сверху камнями и с внутримогильными конструкциями в виде тонких дощатых гробов или долбленных колод отнесены им к средневековью (Талько-Грынцевич, 1928). Будучи врачом, антропологом Ю.Д. Талько-Грынцевич определяет этническую принадлежность этих захоронений, выделяя «все признаки монгольской расы, выступающие только сильнее, чем в черепах современных бурятских и халхаских» и предполагает «что это было одно из племен монгольских, удержавших в более чистом виде свои особенности, вроде крайней короткоголовости, и жило здесь вероятно до пришествия бурят» (Талько-Грынцевич, 1900 , c. 49-50).

После образования Бурят-Монгольской АССР в 1923 году по инициативе историкоэтнологической секции Научного общества им. Д. Банзарова (1924-1930 гг.) средневековье Бурятии исследуют профессиональные археологи.

В 1924 г. Б.Э. Петри в Тункинской долине раскапывает захоронения в «колодах с костями барана при покойниках» с уникальным погребальным инвентарем. В погребениях с надмогильными сооружениями из окатанных булыжников в виде круга в плане были найдены украшения из серебра, золота и жемчуга, бронзовые зеркала, лоскуты шелковой ткани, остатки конской сбруи - стремена и удила, костяные обкладки сложного монгольского лука, наконечники стрел со свистунками и др. предметы (Окладников, 1937, с. 284-290).

В 1925 г. студент Иркутского университета Г.Ф. Дебец произвел раскопки семи погребений в дощатых гробах, обернутых в бересту у дер. Зарубино на левом берегу р. Селенги. На основе однотипного погребального обряда, сопровождающего инвентаря, а также аналогии с уже известными погребениями, исследованными Ю.Д. Талько-Грынцевичем, Г.Ф. Дебец датировал их началом II-го тыс. н.э. и предположительно связал с «древними» монгольскими племенами (Дебец, 1926, с. 16). В апреле 1927 года А.П. Окладников в низовьях р. Селенги обнаружил разрушенные погребения «курумчинских кузнецов» (Окладников, 1976, с. 276-280).

В 1928-29 гг. первая Бурят-Монгольская археологическая экспедиция АН СССР под руководством Г.П. Сосновского исследовала долину р. Селенги на всем ее протяжении и приустьевые участки ее притоков - рек Чикоя и Джиды. Экспедицией открыты и частично исследованы ранее неизвестные средневековые могильники - Саянтуй, Тапхар, Еныскей, Кумын, Ильмовая падь и др., произведены раскопки и поселения на р. Темник (Сосновский 1928, 1930, 1936). По результатам полевых исследований составлена общая характеристика и периодизация древней истории Бурятии, и карта археологических памятников Западного Забайкалья. К сожалению, большая часть материалов раскопок экспедиции не опубликованы. В черновых записях, хранящихся в Институте материальной культуры в Санкт-Петербурге, Г.П. Сосновский классифицировал памятники I и II тысячелетиями и выделил две стадии Хойцегорскую и Саянтуйскую, датировав первую VII-X вв., вторую XIII - XIV вв. (Архив Института материальной культуры РАН, Фонд Г.П. Сосновского - 42). В эти же годы аспирант ГАИМК Э.Р. Рыгдылон исследует Ацагатские скальные погребения (древнебурятские) позднего средневековья. В послевоенные годы (1947-1958 гг.) в Бурятии работает вторая Бурят-Монгольская археологическая экспедиция под руководством А.П. Окладникова, которая охватила предварительным обследованием всю долину р. Селенги и долину р. Уды, вплоть до Еравнинских озер. Им исследованы могильники в районе пос. Наушки и с. Жаргалантуй.

Хронологическая и этническая интерпретация памятников юга и юго-запада Бурятии субъективна. Субъективизм исследователей отражал скудность имеющейся информации 
и общее состояние исторической науки того периода. В результате исследований погребальные памятники - III-VII вв. и X-XIII вв. н.э. не были обнаружены и изучены.

С созданием БКНИИ определилось основное тематическое направление археологических исследований в Бурятии - изучение памятников ранних и поздних кочевников. Е.А. Хамзина с антропологом Н.Н. Мамоновой изучает могильники близ сел Селенга, Сибирь, Вознесеновка, Саратовка и на сопке Тапхар на обоих берегах р. Селенги в центральной Бурятии. В 1963 году исследования продолжены на севере республики, где Е.А. Хамзиной раскопаны могильники близ сел Баянгол и Телятниково. Материалы этих исследований составили основу опубликованной работы «Археологические памятники Западного Забайкалья (Поздние кочевники)» (Хамзина, 1970). Эта работа является первым монографическим исследованием средневековых могильников, в которой предложена новая периодизация, типология памятников и предпринята попытка идентифицировать их по этнической принадлежности. Автор выделил три территориальные группы памятников - на юге, в центре и на севере Бурятии. Южная группа этнически соотносится с селенгинскими уйгурами, центральная, по мнению автора, имела смешанные черты тюркских и монгольских погребальных обрядов, северная (баянгольская, возникшая не ранее VII в.) по погребальному ритуалу близка к культуре курыкан, но имела самостоятельную линию развития. Е.А. Хамзиной предложена периодизация средневековых памятников, в которой наряду с известными этапами - хойцегорским (VII-X вв.) и саянтуйским (XIII-XIV вв.), вводится новый - тапхарский (X-XIII вв.).

В начале 1970 -х годов исследования охватили восточные районы республики - Еравнинский, Кижингинский, Хоринский. Экспедицией под руководством Л.Г. Ивашиной в котловине Еравнинских озер раскопаны 23 погребения. Собранный материал систематизирован и опубликован Л.Р. Кызласовым, который предложил оставить введенные Г.П. Сосновским и Е.А. Хамзиной названия групп или типов погребений, но с внесением изменений в их содержание и хронологию, выделяя при этом две культуры: хойцегорскую - IX-X вв. и саянтуйскую XIII-XIV вв., промежуточный этап - тапхарский (по Е.А. Хамзиной) не выделяет, ссылаясь его на слабую изученность (Кызласов, 1981, c. 59).
В конце 1980-х годов П.Б. Коновалов и С.В. Данилов исследовали 8 объектов из 26 курганов средневекового могильника у с. Кибалино. Был подробно описан ритуал - положение костяков в могилах на спине, головой на северо-северо-восток и северо-восток, неоднородный сопровождающий инвентарь и, в качестве особой черты погребального обряда, отмечено вертикальное положение в изголовье погребенного бараньего стегна. Датировку захоронений авторы ограничили лишь нижней датой, монгольским временем - XI в. H.э.

С середины 1980-х годов исследования по проблемам курыканского наследия (курумчинской культуры) проводил Б.Б. Дашибалов. Им осуществлены раскопки погребальных комплексов в Приольхонье и в Баргузинской долине, проведена тщательная источниковедческая работа над археологическими и письменно-историческими материалами и на этой основе выполнены оригинальные историкоэтнологические исследования (Дашибалов $1995,2005)$. По мере накопления археологического материала с территории Байкальской Сибири авторское понимание курумчинской культуры менялось и вслед за Г.Н. Румянцевым, который показал, что этнонимы «курыкан» орхонских надписей, «гулигань» китайских летописей, «кури» и «фури» средневековых мусульманских авторов и «хори» монгольских народов являются одним и тем же названием, записанным на разных языках, приходит к выводу, что курумчинская культура рассматривалась на ранних этапах VI-X вв. как принадлежащая тюркоязычным курыканам, а в XI-XIV вв. эта культура трансформируется в культуру хори-монголов. Анализируя средневековые погребальные памятники, Б.Б. Дашибалов подверг сомнению утвердившееся мнение о том, что могилы саянтуйского типа, систематизированные Г.П. Сосновским, отражают процесс расселения монголоязычных племен в регионе в начале II тыс. н.э. Согласно его точке зрения столь важное положение не имеет под собой достаточных оснований. На основании сопоставления внутримогильных конструкций и погребального обряда, тюркоязычного населения Тувы, Минусинской котловины и Алтая Б.Б. Дашибалов считает, что погребения в бересте, колоде, с подбоями, каменных ящиках привнесены тюркоязычными племенами, в частности селенгинскими уйгурами (Дашибалов, 2001, с. 59, 62-63).

В 1977-90 гг. археологами ИМБТ СО РАН были продолжены исследования в централь- 


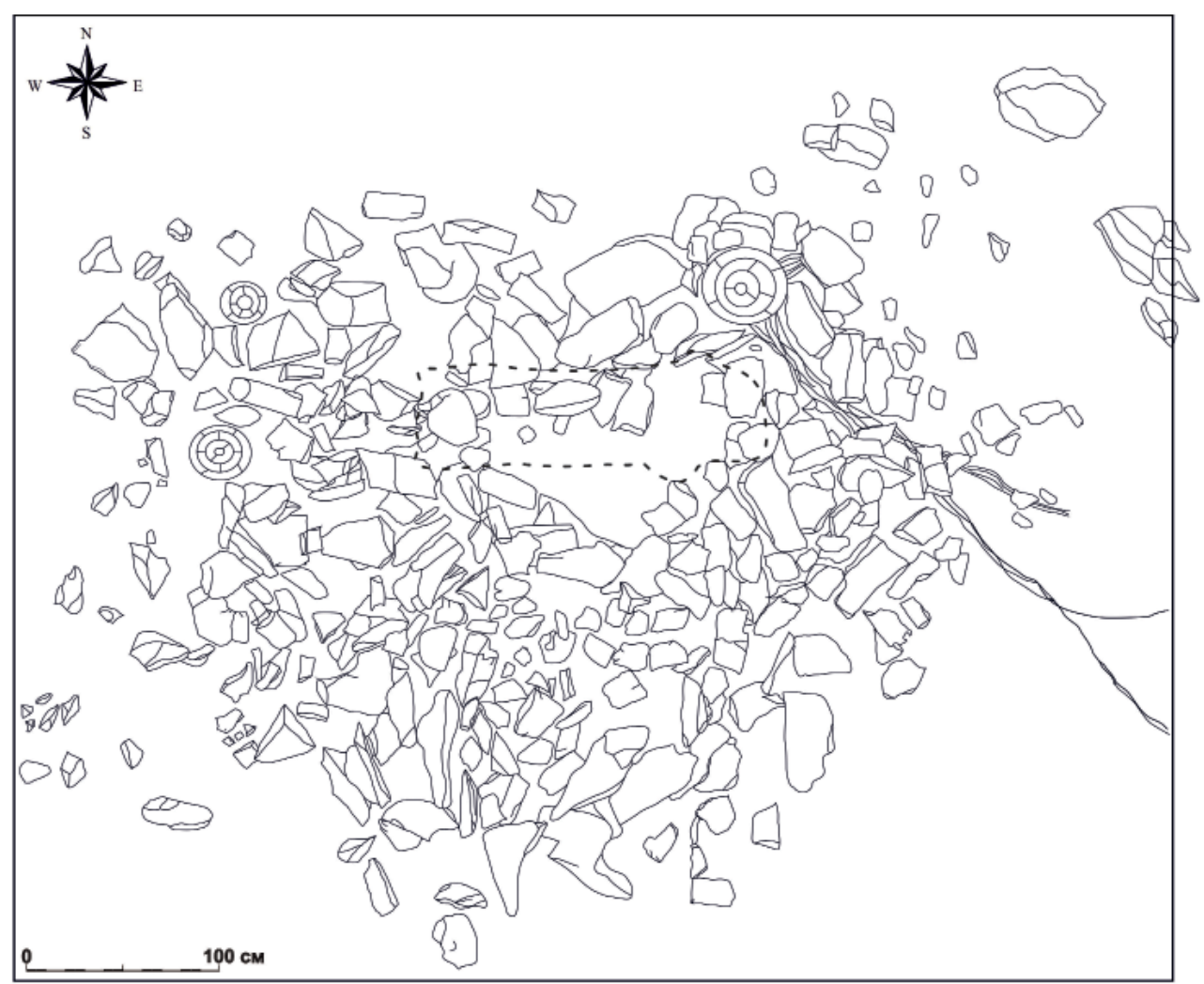

Рис. 2. Могильник Нижний Мангиртуй. Пункт 1, могила 1. План надмогильной кладки

Fig. 2. Nizhniy Mangirtuy burial ground 1, tomb 1. Plan of funeral construction

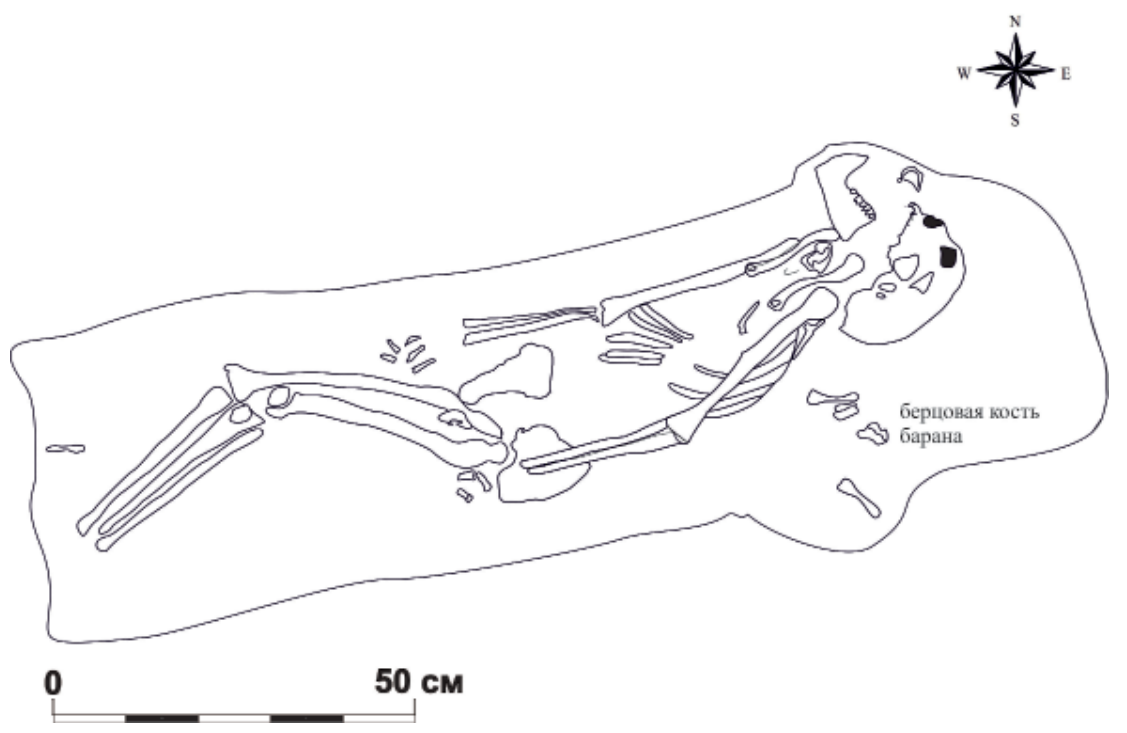

Рис. 3. Могильник Нижний Мангиртуй. Пункт 1, могила 1. План погребения Fig. 3. Nizhniy Mangirtuy burial ground 1, tomb 1. Plan of burial

ной Бурятии: раскопкам подверглись могильники в Дырестуйском Култуке, в пади Подчерной, на горе Хойцегор, в Балеевке, близ с. Енхор. Раскопанные захоронения датируются в достаточно широких хронологических рамках - от VII до XIV вв.

Затем наступает период, когда средневековые погребения в Бурятии практически не раскапываются. Представленные ниже два пункта средневекового могильника Нижний Мангиртуй и отдельное погребение второго пункта могильника Нур-Тухум были открыты и исследованы в рамках поисковых работ по хуннской археологической тематике.

\section{Могильник Нижний Мангиртуй.} Пункты 1 и 2.

Могильник расположен в Бичурском районе Республики Бурятия, на правом берегу р. Хилок и приурочен к юго-западному выступу Заганского хребта (рис. 1.). Объект был выявлен в результате поиска хуннского могильника, который был бы связан с расположенным 


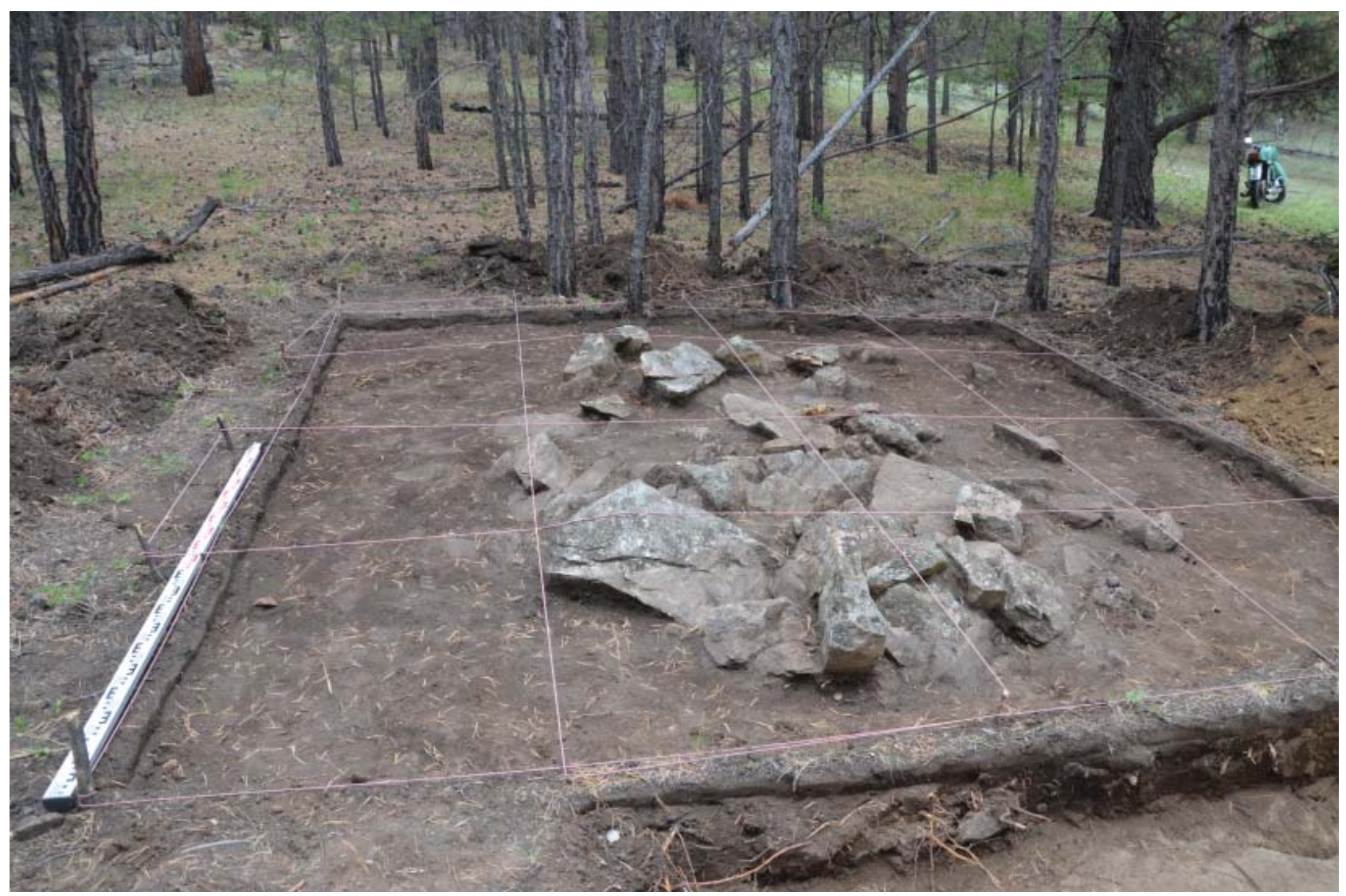

Рис. 4. Могильник Нижний Мангиртуй. Пункт 2, могила 2. Надмогильная кладка. Вид с запада Fig. 4. Nizhniy Mangirtuy burial ground 2, tomb 2. Funeral construction. View from west

здесь неукрепленным хуннским поселением. Интересно, что летом 1899 г. в этих местах c археологической разведкой побывал Ю.Д. Талько-Грынцевич, который кратко охарактеризовал результаты своей поездки следующими словами: «дорога из Верхнего в Нижний Мангиртуй, как и это последнее село, никаких древних памятников не представляет» (Талько-Грынцевич, 1999, с. 97). Спустя 88 лет после посещения Ю.Д. Талько-Грынцевичем этого места в 1987 г. Л.В. Лбовой недалеко от с. Нижний Мангиртуй было открыто хуннское поселение (Лбова, 1988, с. 24-26), а еще через 31 год после открытия поселения нами был открыт этот могильник, который по результатам исследований оказался средневековым.

Пункт 1 находится в 1,2 км восточнее села Нижний Мангиртуй. Могилы первого пункта находятся на водоразделе, а также на мысообразных выступах и пологих «полках» изолированного горного распадка в местности «Пещера».

Надмогильная конструкция могилы №1 первого пункта являлась многослойной, округлой, с западиной в центральной части (рис. 2.). Диаметр надмогильного сооружения 3,8 м, западины - 1,1 м. Максимальная высо- та каменного кургана составляла 65 см. На глубине 50 см выявлена могильная яма длиной - 161 см, шириной - 40 см. Само захоронение было расчищено на глубине 60 см. Погребенный ориентирован головой на восток-северовосток (азимут $46^{\circ}$ ). Костяк на правом боку, ноги слегка подогнуты. Нижняя челюсть была зафиксирована отдельно, расположена выше черепа (вероятно, деятельность землероек). В районе левого плеча были обнаружены кости ноги барана.

Пункт 2 находится в 0,7 км юго-восточнее села Нижний Мангиртуй. Могилы второго пункта расположены на высоком мысу западного склона подгорного шлейфа, обращенного в сторону р. Мангиртуйки. Раскопкам подверглись две могилы, одна из которых оказалась кенотафом.

Надмогильная конструкция могилы №2 второго пункта имела овальную форму, вытянутую по линии восток-запад (рис. 4). Здесь в скальнике была выдолблена ниша, в которую помещен погребенный на правом боку с согнутыми ногами. Череп отделен от скелета и помещен в небольшую нишу. Сам скелет ориентирован на северо-восток (азимут 55) (рис. 5.). Справа и слева от костяка в районе грудного отдела обнаружены два костяных черешко- 


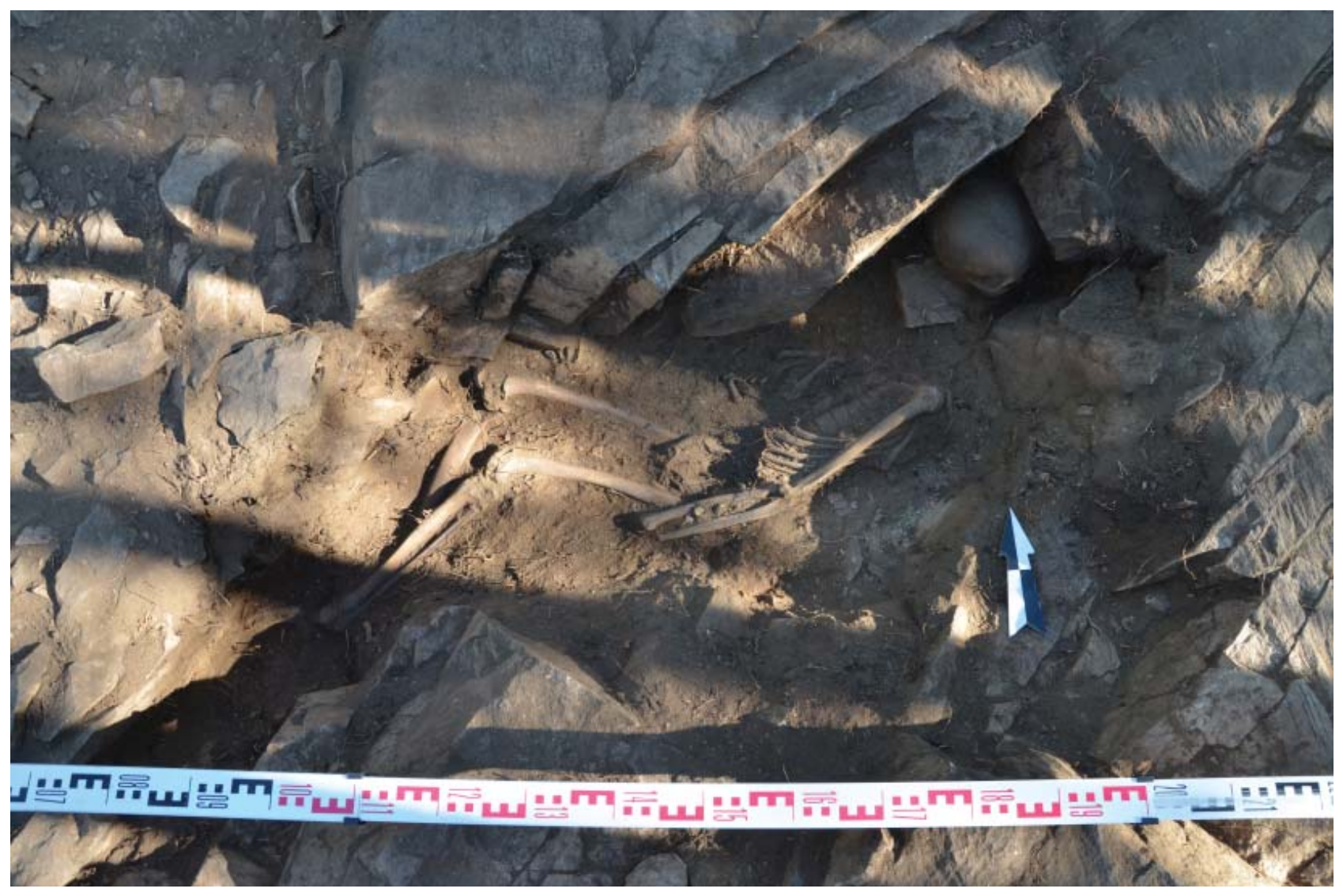

Рис. 5. Могильник Нижний Мангиртуй. Пункт 2, могила 2. Погребение.

Fig. 5. Nizhniy Mangirtuy burial ground 2, tomb 2. The burial

вых наконечника стрел. Стрелы располагались острием вверх. Ширина ниши от 42 см в верхней части до 16 см в ногах. Глубина захоронения составляет 52 см.

Очевидно, что два пункта этого могильника можно было бы отнести к двум разным хронологическим этапам раннемонгольской археологической культуры. Первый пункт могильника можно было датировать XI-XIV вв., т.е. саянтуйским этапом. На это указывает наличие в погребении берцовой кости барана, но этот признак перестал быть культурно-диагностирующим, поскольку встречается и в могилах хойцегорского этапа. Второй пункт могильника датируется хойцегорским этапом (VII-X вв.) и поддержана радиоуглеродной датой, указывающей на VII в. (COAH-9885).

\section{Могильник Нур-Тухум. Пункт 2}

Могильник расположен в Селенгинском районе Республики Бурятия (рис. 1.). Пункт 2 могильника Нур-Тухум находится в 0,4 км юго-западнее пункта 1 в местности Губэй. Могилы располагаются у подножия увала с северо-восточной стороны. Всего в могильнике насчитывается 33 погребения, 32 из которых хуннские. Средневековое погребение № 1 располагалось на седловине, обосо- бленно. Каменная кладка округлой формы с небольшой западиной посередине (рис. 6). Диаметр надмогильной конструкции - 6 м. Длина могильной ямы - 1,8 м, ширина - 55 см. Костяк располагался на глубине 60-62 см. Ориентирован головой на восток. Положение на спине. Правая рука согнута, фаланги кисти руки расположены на тазовых костях. Левая рука прямая. Ноги слегка сдвинуты в южном направлении. В районе левого плеча были обнаружены кости ноги барана (рис. 3.). В районе груди обнаружены три бусины красного цвета. Между ног зафиксированы остатки небольшого, полностью проржавевшего, железного ножа острием вниз (рис. 7).

Здесь мы при датировании также не можем опираться на такой признак как наличие в погребении кости ноги барана. Возможно, данное погребение было связано со средневековым поселением, расположенным в 0,5 км к востоку. Полученные радиоуглеродные даты указывают на время функционирования поселения в XIV-XV вв. (Базаров, Миягашев, 2018, с. 93).

Таким образом, археологические памятники средневековья в Западном Забайкалье, пожалуй, являются наиболее актуальной областью исследований по истории Буря- 


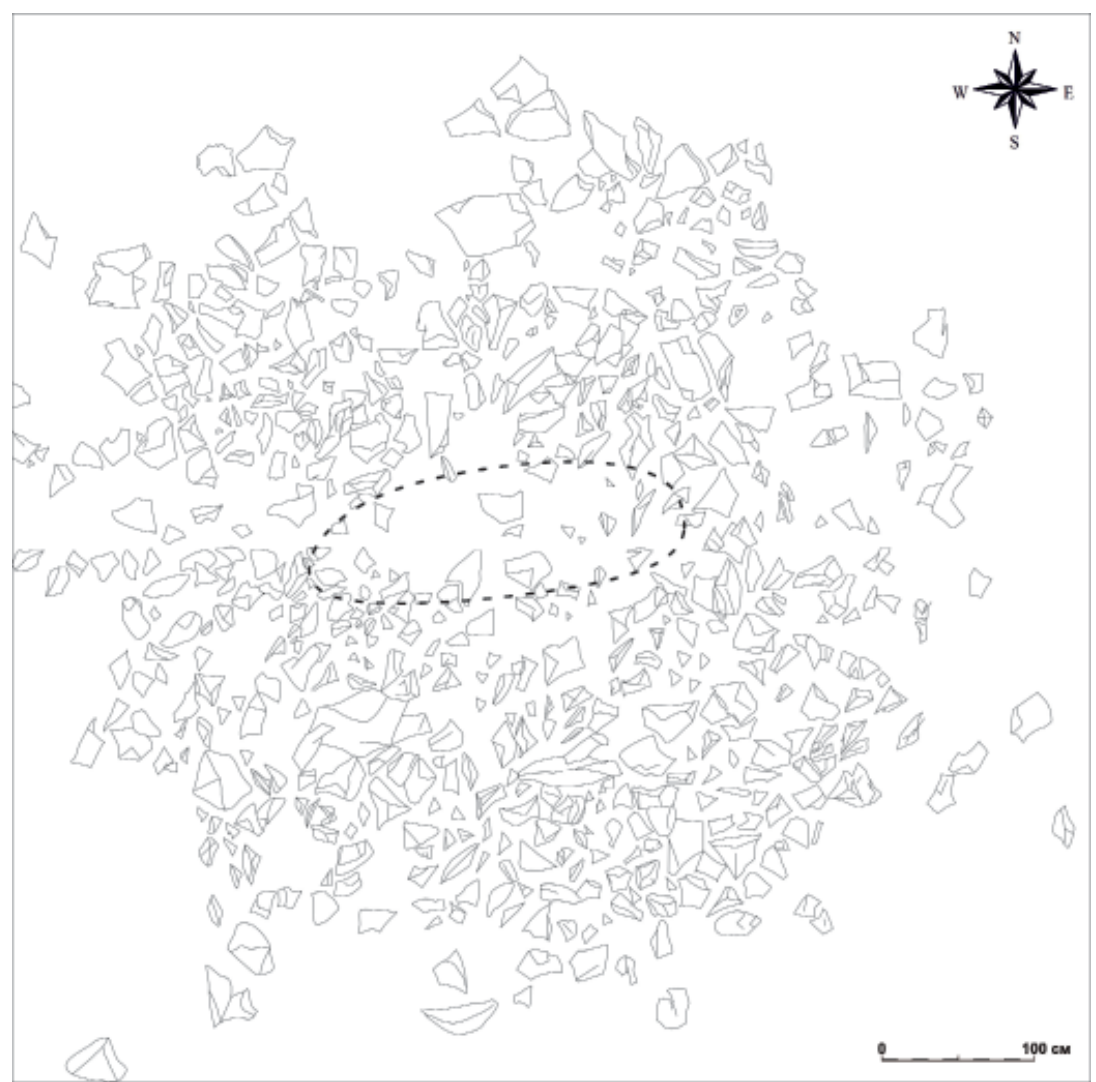

Рис. 6. Могильник Нур-Тухум. Пункт 2, могила 1. План надмогильной кладки Fig. 6. Nur-Tukhum burial ground 2, tomb 1. Plan of funeral construction

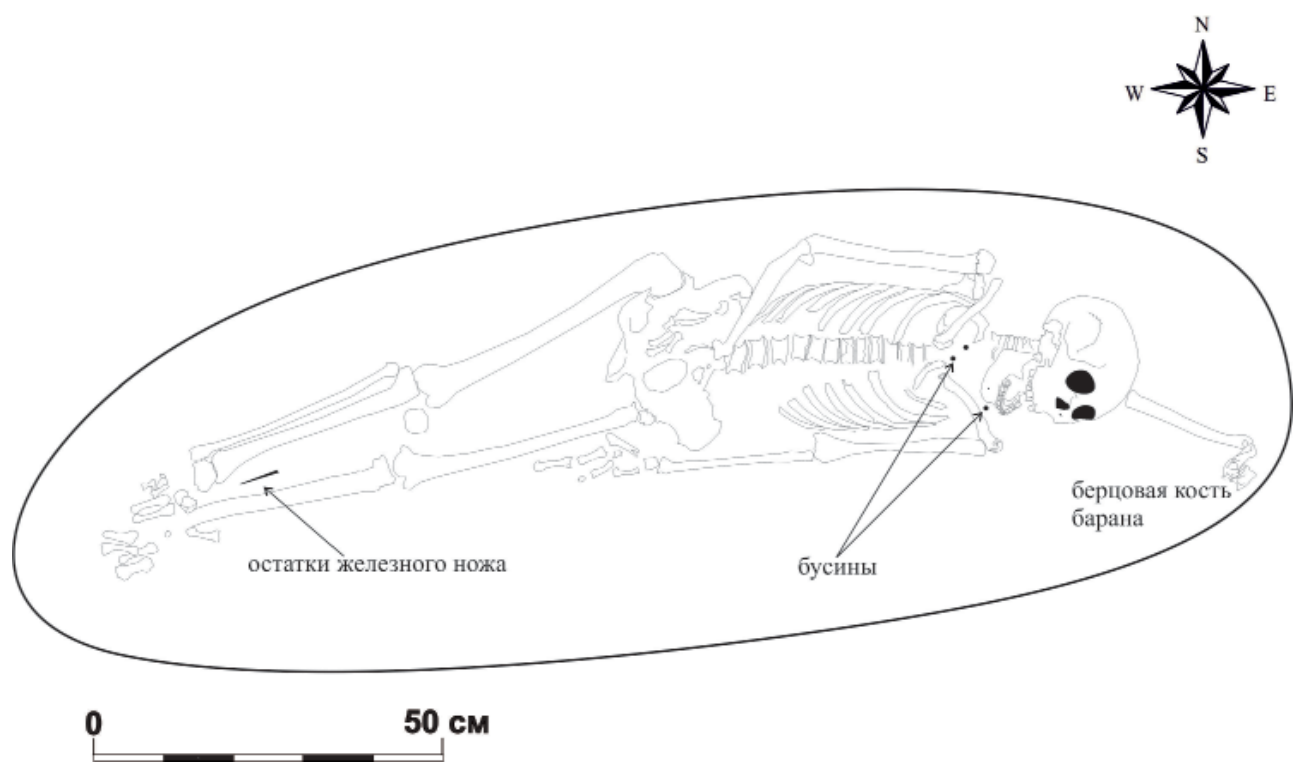

Рис. 7. Могильник Нур-Тухум. Пункт 2, могила 1. План погребения.

Fig. 7. Nur-Tukhum burial ground 2, tomb 1. Plan of burial

тии в силу остроты дискуссионной проблемы тюрко-монгольского взаимодействия в данном регионе. Информативны в этом аспекте погребальные комплексы, т.е. могилы с одинаковым устройством, единым обрядом захоронения и одинаковым инвентарным комплексом. Одним из сложных вопросов является выявление и исследование синхронных стоянок и поселений средневековья, материалы которых можно было бы привлечь для сопоставительных процедур. В данном случае перспективным видится дальнейшее исследование Нур-Тухумского археологического комплекса, включающего в себя и поселенческий, и погребальные материалы.

На сегодняшний день существуют три точки зрения о культурной принадлежности и датировки погребальных памятников средневековья: 1) выделяются две археологические культуры: хойцегорская культура 
(VII-X вв.) и саянтуйская культура (XI-XIV вв.), являющиеся различными в этническом плане - уйгуры и монголы (Хамзина Е.A., Кызласов Л.Р., Ивашина Л.Г.); 2) раннемонгольская культура с двумя этапами развития - хойцегорский (VII-X вв.) и саянтуйский (XI-XIV вв.) (Коновалов П.Б., Данилов С.В., Именохоев Н.В.); 3) саянтуйский тип (2-е тысячелетие н.э.) - селенгинские тюркоязычные племена (Дашибалов Б.Б.).

В недавно вышедшем втором томе Истории Сибири предлагается раннемонгольскую археологическую культуру ограничить доимперским периодом, где верхним рубежом будет являться время конца XII - начала XIII в., когда культура монгольских народов переживала период становления и консолидации. Эпоху Великой империи XIII-XIV вв., когда полностью оформилась и устоялась в своих основных признаках общегосударственная культура, называть просто монгольской. Хойцегорский и саянтуйский этапы остаются в рамках раннемонгольской археологической культуры, но должна измениться их хронология. Указывается, что ранние памятники раннемонгольской культуры, которые можно было бы уверенно отнести к I тыс. н.э. до сих пор достоверно не выявлены (История..., 2019, 309). Эта проблема связана также с отсутствием радиоуглеродных датировок по средневековым погребениям. Небольшая серия радиоуглеродных дат опубликована только для северной группы средневековых погребений (Дашибалов, 2011, c. 68).

Безусловно, настоящее выделение археологических культур тюрко-монгольского периода Бурятии носит временный и субъективный характер. Проблема выделения археологических культур достаточно сложная и решается во многих случаях неоднозначно, особенно при рассмотрении кочевых сообществ с их «подвижными» территориальными границами. Главной проблемой является определение оптимальных признаков идентификации археологических культур. И, конечно же, не на последнем месте находятся вопросы хронологии, которые будут и должны решаться при помощи радиоуглеродного метода датирования.

\section{ЛИТЕРАТУРА}

Бичурин Н.Я. (Иакинф) Записки о Монголии. СПб., 1828. Т.2. 241 с.

Дашибалов Б.Б. Археологические памятники курыкан и хори. Улан-Удэ: БНЦ СО РАН, 1995. 191 с.

Дашибалов Б.Б. На монголо-тюркском пограничье (Этнокультурные процессы в Юго-Восточной Сибири в средние века). Улан-Удэ: БНЦ СО РАН, 2005. 202 с.

Дашибалов Б.Б. Древности хори-монголов: хунно-сяньбийское наследие Байкальской Сибири. Улан-Удэ: Бурятский госуниверситет, 2011. 174 с.

Дашибалов Б.Б. Об этнической принадлежности могил саянтуйского типа Юго-Восточной Сибири // Бурятия: проблемы региональной истории и исторического образования. Ч. 1. / отв. ред. Т. Е. Санжиева, С. В. Бураева, Ю. Б. Санданов. Улан-Удэ: Бурят. госуниверситет, 2001. С. 58-67.

Дебеи Г.Ф. Могильник железного периода у с. Зарубино // Бурятиеведение. 1926. №2. С. 14-16.

История Бурятии: в 3 т. Т.1. Древность и средневековье / Гл. ред. Б. В. Базаров. Улан-Удэ: Изд-во БНЦ СО РАН, 2011. $328 \mathrm{c.}$

История Сибири: Том 2: Железный век и Средневековье / отв. ред. В.И. Молодин. Новосибирск: ИАЭТ СО РАН, 2019. $643 \mathrm{c}$.

Кириллов Н.В. Несколько указаний на археологические остатки в Верхнеудинском округе // Известия ВСОИРГО. 1897. Т. 28. Вып. 2. С. 136-143.

Кызласов Л.Р. Средневековые памятники Западного Забайкалья (IX-X вв.) // Степи Евразии в эпоху средневековья / Археология СССР / Отв. ред. С.А. Плетнева. М.: Наука, 1981. С. 59-61.

Лбова Л.В. Отчет об археологическом обследовании долины р. Хилок в 1987 г. (Бичурский район, Бурятская АССР). Улан-Удэ, 1988. 93 с. // НОА ИА РАН. Ф-1. Р-1. № 12198.

Лопатин И.А. Краткий отчет о действиях Витимской экспедиции в 1865 г. // Записки ВСОРГО. 1867. Кн. 9. С. $508-526$.

Окладников А.П. Очерки из истории западных бурят-монголов (XVII-XVIII вв.) Л., 1937. 428 с.

Окладников А.П. Предварительное сообщение об археологических разведках в окрестностях Кабанска // Окладников А.П. История и культура Бурятии. Улан-Удэ: Бурятское кн.изд-во, 1976. С. 276-279.

Сосновский Г.П. Краткий отчет о летней работе археол. отряда Бурят-Монгольской экспедиции АН СССР в 1928 г. // Бурятиеведение. 1928. № 4. С. 162-166. 
Сосновский Г.П. Археологическая Бурят-Монгольской экспедиция // Отчет о деятельности Академии наук СССР за 1929 год. Вып. 2. / сост. В. Л. Комаров. Л.: АН СССР, 1930. С. 153-155.

Сосновский Г.П. Итоги работ Бурят-Монгольского Археологического отряда АН СССР в 19281929 гг. // Проблемы Бурят-Монгольской АССР. Т.2. М.-Л.:АН СССР, 1936. С. 318-321.

Степи Евразии в эпоху средневековья // Археология СССР / Отв. ред. С.А. Плетнева. М.: Наука, 1981. $301 \mathrm{c}$.

Талько-Грынцевич Ю.Д. Материалы к палеоэтнологии Забайкалья // Тр. Троицкосавско-Кяхтинского отделения Приамур. отд. Рус. геогр. об-ва . вып. 3. М., 1900. С. 48-50.

Талько-Грынцевич Ю.Д. Население древних могил и кладбищ забайкальских // Бурятиеведение. 1928. № 1-3 (5-7). С. 91-103.

Талько-Грынцевич Ю.Д. Материалы к палеоэтнологии Забайкалья. Археологические памятники сюнну, вып. 4. СПб.: Фонд "Азиатика", 1999. 123 с.

Хамзина E.A. Археологические памятники Западного Забайкалья (Поздние кочевники). Улан-Удэ, 1970. $142 \mathrm{c}$.

\section{Информация об авторах:}

Базаров Биликто Александрович, научный сотрудник, Институт монголоведения, буддологии и тибетологии СО РАН (г. Улан-Удэ, Россия); biliktobazarov@yandex.ru

Именохоев Николай Владимирович, научный сотрудник, Институт монголоведения, буддологии и тибетологии СО РАН (г. Улан-Удэ, Россия); yni@mail.ru

Миягашев Денис Алексеевич, кандидат исторических наук, научный сотрудник, Институт монголоведения, буддологии и тибетологии СО РАН (г. Улан-Удэ, Россия); silker10@yandex.ru

Дикий Ярослав Витальевич, кандидат исторических наук, младший научный сотрудник, Институт монголоведения, буддологии и тибетологии СО РАН (г. Улан-Удэ, Россия); yaroslavdikii@gmail.com

\section{REFERENCES}

Bichurin, N. Ya. (Iakinf). 1828. Zapiski o Mongolii (Notes on Mongolia). Sain-Petersburg. Vol. 2 (in Russian).

Dashibalov, B. B. 1995. Arkheologicheskie pamyatniki kurykan i khori (Archaeological Sites of the Kurykan and Khori). Ulan-Ude: Buryatia Scientific Center of the Siberian Branch of the Russian Academy of Sciences (in Russian).

Dashibalov, B. B. 2005. Na mongolo-tyurkskom pogranich'ye (Etnokul'turnye protsessy v Yugo-Vostochnoy Sibiri v sredniye veka) (On the Mongol-Turkic Borderland (Ethnocultural Processes in South-Eastern Siberia in the Middle Ages). Ulan-Ude: Buryatia Scientific Center of the Siberian Branch of the Russian Academy of Sciences (in Russian).

Dashibalov, B. B. 2011. Drevnosti khori-mongolov: khunno-syan'biyskoe nasledie Baykal'skoi Sibiri (Antiquities of the Khori-Mongols: the Hunno-Xianbei Heritage of Baikal Siberia). Ulan-Ude: Buryat State University (in Russian).

Dashibalov, B. B. 2001. In Sanzhieva, T. E., Buraeva, S. V., Sandanov, Yu. B. (eds.). Buryatiia. Problemy regional'noi istorii i istoricheskogo obrazovaniia Buryatia (Buryatia: Issues of Regional History and Historical Education). 1. Ulan-Ude: Buryat State University, 58-67 (in Russian).

Debets, G. F. 1926. In Buryatiyevedeniye (Buryatia Studies). 2, 14-16 (in Russian).

Kirillov, N. V. 1897. In Izvestiya Vostochno-Sibirskogo Otdela Imperatorskogo Russkogo Geograficheskogo obshchestva (Reports of the East-Siberian Departament of the Imperial Russian Geographic Society) 28 (2), 136-143 (in Russian).

Kyzlasov, L. R. 1981. In Pletneva, S. A. (ed.). Stepi Evrazii v epokhu srednevekov'ia (Eurasian Steppes in the Middle Ages). Archaeology of the USSR 18. Moscow: "Nauka" Publ., 59-61 (in Russian).

Bazarov, B. V. 2011. (ed.). Istoriua Buriatii: v 3 t. T.1. Drevnost' i srednevekov'e (History of Buryatia: in 3 volumes. Vol. 1. Antiquity and the Middle Ages). Ulan-Ude: Buryatia Scientific Center of the Siberian Branch of the Russian Academy of Sciences (in Russian).

Molodin, V. I. 2019 (ed.). Istoriya Sibiri. T 2: Zheleznii vek $i$ Srednevekov'e (History of Siberia. 2. The Iron Age and the Middle Ages). Novosibirsk: Institute of Archaeology and Ethnography of the Siberian Branch, Russian Academy of Sciences (in Russian).

Lbova, L.V. 1988. Otchet ob arkheologicheskom obsledovanii doliny r. Khilok v 1987 g. (Bichursky District, Buryatskaya ASSR) (Report on the Archaeological Survey of the Valley of the Khilok River in 1987 
(Bichursky District, Buryat ASSR). Ulan-Ude. Archive of the Institute of Archaeology of the RAS, F. -1. R-1, D. 12198 (in Russian).

Lopatin, I. A. 1867. In Zapiski Sibirskogo otdeleniia Russkogo geograficheskogo obshchestva (Proceedings of Siberian Departament of the Imperial Russian Geographic Society) 9, 508-526 (in Russian).

Okladnikov, A. P. 1927. Ocherki iz istorii zapadnykh buriat-mongolov (XVII - XVII vv.) (Essays on the History of Western Buryat-Mongols (1 $7^{\text {th }}-18^{\text {th }}$ cc.)). Leningrad (in Russian).

Okladnikov, A. P. 1976. In Okladnikov, A. P. Istoriia i kul'tura Buriatii (History and Culture of Buryatia). Ulan-Ude: "Buriatskoe knizhnoe izdatel'stvo" Publ., 276-279 (in Russian).

Sosnovsky, G. P. 1928. In Buryatiyevedeniye (Buryatia Studies) 4, 62-166 (in Russian).

Sosnovskiy, G. P. 1930. In Komarov, V. L. (comp.). Otchet o deiatel'nosti. Akademii nauk SSSR za 1929 god (Report on the Activities of the Academy of Sciences of the USSR in 1929) 2. Leningrad: Academy of Sciences of the USSR, 153-155 (in Russian).

Sosnovsky, G. P. 1936. In Problemy Buriat-Mongol'skoi ASSR (Problems of the Buryat-Mongolian ASSR). T.2. Moscow-Leningrad.: Academy of Sciences of the USSR, 318-321 (in Russian).

Tal'ko-Gryntsevich, Yu. D. 1900. In Trudy Troitskosavsko-Kiakhtinskogo otdeleniia Priamurskogo otdeleniia Russkogo geograficheskogo obshchestva (Proceedings of the Troitskosavsko-Kyakhtinsky Subbranch of the Priamursky Branch of the Russian Geographical Society) 3. Moscow, 48-50 (in Russian).

Tal'ko-Gryntsevich, Yu. D. 1928. In Buryatiyevedeniye (Buryatia Studies) 5-7 (1-3). 91-103 (in Russian).

Tal'ko-Gryntsevich, Yu. D. 1999. Materialy k paleoetnologii Zabaykal'ia. Arkheologicheskiye pamyatniki syunnu (Materials for the paleoethnology of Transbaikalia. Archaeological Sites of the Xiongnu). 4. Saint Petersburg: Fund "Asiatica" (in Russian).

Khamzina, E. A. 1970. Arkheologicheskie pamiatniki Zapadnogo Zabaykal'ia (Pozdniie kochevniki). Archaeological sites of Western Transbaikalia (Late Nomads). Ulan-Ude (in Russian).

\section{About the Authors:}

Bazarov Bilikto A. Institute for Mongolian, Buddhist and Tibetan Studies of Siberian Branch of Russian Academy of Sciences, Sakhyanovoi Str., 6, Ulan-Ude, 670047, Russian Federation; biliktobazarov@yandex. $\mathrm{ru}$

Imenokhoev Nikolay V. Institute for Mongolian, Buddist and Tibetan Studies of Siberian Branch of Russian Academy of Sciences, Sakhyanovoi Str., 6, Ulan-Ude, 670047, Russian Federation; yni@mail.ru

Miyagaschev Denis A. Candidate of Historical Sciences. Institute for Mongolian, Buddhist and Tibetan Studies of Siberian Branch of Russian Academy of Sciences, Sakhyanovoi Str., 6, Ulan-Ude, 670047, Russian Federation; silker10@yandex.ru

Dikiy Yaroslav V. Candidate of Historical Sciences. Institute for Mongolian, Buddhist and Tibetan Studies of Siberian Branch of Russian Academy of Sciences, Sakhyanovoi Str., 6, Ulan-Ude, 670047, Russian Federation; yaroslavdikii@gmail.com

Статья поступила в журнал 01.04.2021 г. Статья принята к публикации 01.04.2021 г. Авторы внесли равноценный вклад в работу. 